Figures relating to patients detained as Subnormal or Severely Subnormal under the Mental Health Act and to Tribunal applications (9 January) are of interest. 514 patients were detained under Section 26 and 721 under Sections 60 etc. There were 55 Tribunal applications from Section 26 patients and $3^{8}$ from Section 60 patients, as well as 85 references to Tribunals relating to Section 65 patients.

There was a question on 12 January about the incidence of Down's syndrome-the number reported (a necessarily incomplete figure) had fallen from 547 in 1970 to 384 in 1976 .

Addiction

Some particulars of research on alcoholism were given on 15 February. MRG projects were being undertaken into alcoholism and drinking habits in Camberwell, in the Shetlands, among distillery workers, and others.

Detoxification units have been set up in Leeds and Manchester.

It is still not considered advisable to include barbiturates under the Misuse of Drugs Act; the results of the CURB campaign have not yet been evaluated.

A single death doubtfully attributed to the effects of thioridazine was not thought to necessitate a special inquiry.

Alexander Walk

\title{
THE PHARMACEUTICAL INDUSTRY AND SPONSORED MEETINGS
}

In 1968 a Medico-Pharmaceutical Forum was established jointly by the Royal Medical and Surgical Colleges, established Medical Institutions and representatives from the Pharmaceutical Industry, for the purpose of providing a setting for the discussion of problems of mutual interest to the medical profession and to the industry. In 1976 the Forum set up a Working Party "to review the present and consider the desirable future role of the Pharmaceutical Industry in the continuing education of doctors and to make recommendations.' The Working Party's report was published in April 1978.* The Report includes an agreement between the Association of the British Pharmaceutical Industry, the National Association of Clinical Tutors and the Advisory Committee of Deans of the Council for Postgraduate Medical Education in England and Wales on the terms and conditions under which sponsorship of meetings in Postgraduate Medical Centres is permitted, as follows-(1) Meetings sponsored by a pharmaceutical house may be allowed subject to the decision of the clinical tutor or the local Postgraduate Medical Education Committee: (2) Arrangements for all sponsored meetings should always be made through the clinical tutor or the Committee, and staff from the sponsoring pharmaceutical house should be invited to attend: (3) Some vetting of lecture material and films should always be undertaken: (4) An independent opinion by a doctor sufficiently experienced in the topic should always be available at such meetings: (5) Publicity by the pharmaceutical house is allowed,

*The Report is obtainable from The Medico-Pharmaceutical Forum, I Wimpole Street, London WIM 8AEPrice per copy $£ 3.00$. but should be separate from the educational content of the meeting; (6) Sponsorship by the pharmaceutical house should be limited to the provision of light refreshments and the printing of programmes, and due acknowledgements should be made, and (7) Meetings sponsored to a greater extent than stated in paragraph 6 cannot be approved under Section 63; such meetings may be recognized for seniority payments (which are no longer linked with attendance at postgraduate educational sessions) and the postgraduate training allowance on application by the Postgraduate Dean to the DHSS.

The Education Committee understands that the payment of fees as well as travelling expenses to speakers may be included as part of the cost of running the meeting which a drug firm could be asked to pay. The main concern of the Council for Postgraduate Medical Education is to prevent the payment of speakers directly. In addition, although the Council's statement refers to meetings in Postgraduate Medical Centres, it is considered advisable to apply the same general rules to meetings held elsewhere, for example, in psychiatric hospitals. Postgraduate Deans would therefore wish to be informed of all arrangements involving a pharmaceutical house and would clearly prefer the financial transactions to be dealt with by their offices once the clinical tutor has negotiated the preliminary arrangements.

The Medico-Pharmaceutical Forum has expressed a willingness to try to help any tutors who experience difficulties with the arrangements.

E. B. O. SMrTH

Secretary, Education Committee 